\title{
Effect of Hatching Eggs Storage and Maternal Age on Internal Egg Characteristics
}

\author{
Mahdi Salih Mohammad Al-Kerwi ${ }^{\text {a)}}$, Ammar subhy Shaker, Faez Saleh Mohammad and Hawraa \\ G.T.Al-Shebani
}

Faculty of Agriculture, University of Al-Qadisiah, Iraq.

a) Corresponding Author: mahdi.mohammad@qu.edu.iq

\author{
Received : 22/6/2021 \\ Acceptance : $12 / 8 / 2021$ \\ Available online: $31 / 12 / 2021$
}

\begin{abstract}
The current review showed that storing eggs for a period of more than 7 days affects the quality, the internal characteristics of the eggs and the extent of survival of the embryo during the periods of egg storage and subsequent incubation. Besides, the dam age also has an effect that interferes with the length of the storage period. Increasing the length of storage period causes a negative decrease in the egg characteristics of old breeders (breeders $<53$ weeks of age) and young ones. The decrease is more pronounced in some of the characteristics of the eggs of small flocks compared to the older ones, such as the increase in the $\mathrm{pH}$ of albumin, as well as the morphological changes of the embryo that increase with the increase in the length of the storage period, but this increase is more pronounced in the younger flocks than in the larger ones. Storing the ggs for a short period $(<7$ days $)$ does not reduce the hatching rate of the eggs of young breeders, this may be due to the lack of fluidity of the albumin and the availability of oxygen to the embryo. Increasing the length of storage period affects negativelythe hatched chicks charactoristics ( young and old broodstock). The interaction between length of egg storage and the age of the breeders on the characteristics of hatched chicks is not sufficiently clear. It can be concluded from this study that storing eggs for a short period improves the hatchability rate of the of young mothers, not of old ones. The negative effect of prolonged egg storage has less effect on the eggs of young breeders than eggs of older ones. The conditions of egg storage have an important effect on the characteristics of hatching and hatched chicks when storing eggs for a long time.
\end{abstract}

Keywords. Egg storage, Eggs characteristics, Embryos development.

\section{INTRODUCTION}

The hatching process is one of the important operations in raising poultry. With the development of the poultry industry, the demand for hatching eggs increased, which necessitated an increase in the hatching rate and the production of high specification hatchlings.

From an economic point of view, it was found that an increase in hatching rate by $1 \%$ for the eggs of mothers of broilers and broilers increases the profits of companies in the United States of America by more than 23 million dollars annually (Schaal and Cherian, 2007). Therefore, the owners of hatchery projects strive to achieve two aims that guarantee the highest economic returns, which are the production of Yemeni eggs and the achievement of a high hatchability ratio with hatcheries that are healthy and active to meet the growing demand for poultry meat, so the demand for this meat is expected to increase by $60 \%$ during the next twenty years. After the process of laying the eggs by the mothers, they are collected and stored in cooled stores and then transferred to the hatchery where they are stored again, after which they are sterilized and warmed before being placed in the incubator. Accordingly, the current study aimed to review the effect of the length of storage period of hatching eggs and maternal age and the interaction between them on egg traits and embryonic development.

\section{MATERIALS AND METHODS}

\section{- The Effect of Maternal Age}

The average weight of the egg increases with the increase in the age of the mothers (Tona et al., 2004), and this increase is due to the increase in the weight of albumin and yolk, noting that the increase is more associated with the yolk compared to the albumin, and even in eggs of equal weight, the yolk is heavier in eggs produced from old mothers (Ulme-Franco et al. The increase in yolk weight of the eggs of old mothers is due to the formation and deposition of lipoproteins. As the age of mothers increases, the production of lipoproteins and yolk weight increases, while the amount of fat available in young 
chickens for yolk deposition is low (Nangsuay et al., 2016) Another reason for the increase in yolk weight with increasing maternal age is the increase in the time between ovulation processes, as this caused the deposition of yolk that is synthesized in the liver in fewer ovarian follicles (Sell et al., 1987).The yolk index represents the strength of the yolk membranes, as it decreases approximately from $46 \%$ to $39 \%$ when maternal age ranges from 26 to 56 weeks (Nowaczewski et al., 2010).The $\mathrm{pH}$ of albumin increases at the time of ovulation with increasing maternal age. This increase is parallel to the decrease in the thickness of albumin, where it was observed that the $\mathrm{pH}$ increased from 8.08 to 8.30 when the albumin height was 7.74 and $6.28 \mathrm{~mm}$, respectively, for the eggs of mothers at the age of 59 and 32 weeks, respectively (lapaõ et al., 1999). The Haugh unit (HU) also decreases with the age of mothers, as Tona et al. (2004) indicated that the value of the $\mathrm{H}$ unit was 82.1 and 88.6 when the mothers were 35 and 45 weeks old, respectively, while the albumin viscosity decreases with the age of mothers and the increase in $\mathrm{PH}$ and albumin fluidity.

\section{- The Effect of Long Storage Time}

During egg storage, albumin loses moisture to the yolk through the yolk membranes and to the surrounding air through the process of evaporation from the egg shell. Tona et al., (2001) noticed a decrease in albumin weight by $2.07 \%$ and an increase in yolk weight by $1.82 \%$ after storing eggs for 10 days from young mothers ( 31 weeks) while between Scott and Silverside (2000) that storing eggs led to an increase in yolk weight by $1.14 \%$.Other cases are observed on eggs when stored for more than 14 days, such as the transfer of free amino acids from the yolk to the albumin, and moisture is transferred from the albumin to the yolk through the yolk membranes, which results in a decrease in the hardness of the yolk. The length of the storage period of eggs (Li-Chan et al., 1995). The viscosity of albumin depends on the strength of the ovomucinlaycisum complex (Freeman et al., 1974) and with the increase in the length of the egg storage period and the increase in PH albumin, this complex loses stability, causing a decrease in the albumin thickness (Kato et al. 1970, 1981). The decrease in the viscosity of the albumen occurs at the beginning of the storage days in parallel with the increase in the yolk PH value. As for the yolk index (the ratio between the height and width of the yolk) it increases due to the increase in the moisture of the yolk with the increase in the length of storage period (1975, Heath).

\section{- The Interaction Between Maternal Age and Length of Storage}

The quality of eggs deteriorates with the increase in the length of the storage period, and this is clearly evident in the eggs of young and young mothers in comparison with the eggs of old mothers. Of storage for eggs of young mothers at the age of (32 weeks) by 1.4 compared to 0.87 for eggs of mothers of old age (59 weeks). On the other hand, Mueller, (1959) showed that the decrease in the quality of albumin during the storage period depends on the specification of albumin at the time of ovulation, which depends on the age of the mothers and the unit of identity. Elderly after 8 days of egg storage. Lapaõ et al. (1999) confirmed that albumin PH does not differ between eggs of young mothers and eggs of old mothers, as its value was 9.17 and 9.12, respectively. As for the basal level of albumin when eggs were stored for 8 days, it reached 9.0 at $14{ }^{\circ} \mathrm{C}$. ${ }^{\circ}$ and to 9.5 at a temperature of $38{ }^{\circ} \mathrm{C}$. It has been observed that albumin $\mathrm{PH}$ is more acidic at the time of egg laying in older mothers Compared to the eggs of younger mothers, but the albumin PH of the eggs of young mothers will rise more rapidly than the PH of the eggs of old mothers. The increase in the speed of the rise in the PH value is associated with the fluidity of the albumin, which increases due to the breakdown of the lysosome of ophamucino complex. The amount of this complex in the thick albumin layer is 4 times what is found in light albumin ( Burley and Vadehra, 1989).

\section{EMBRYONIC DEVELOPMENT, METABOLISM AND HATCHING}

\section{- $\quad$ The Effect of Maternal Age}

\section{a. Embryonic Development}

Older chickens (51-54 weeks) produce eggs containing highly developed embryos of -10.39EG, while younger chickens (31-34 weeks) produce eggs with embryonic development of 10.16EG - this phenomenon may be associated with the length of the egg-laying chain which It is shorter in older mothers and thus leads to an increase in the number of the first eggs (Fasenko et al., 1992), as the embryo in the first egg remains in the oviduct for 16 hours more than the rest of the eggs, so the embryo is more developed morphologically. Damaziak et al. (2018) observed a higher stage of embryonic development for eggs of old mothers (70 weeks) 48 hours after being placed in the egg incubator compared to eggs of young mothers at the age of 49 weeks. ) that on the 18th day of egg incubation, the weights of the embryos were higher by $3.7 \mathrm{~g}$ for the eggs of mothers at the age of 52 weeks compared to the eggs of mothers at the age of 36 weeks, as well as longer by $0.8 \mathrm{~cm}$. A decrease in hatching traits, as the percentage of chicks that were culled increased from $0.85 \%$ to $1.8 \%$ for mothers' eggs at 33 and 62 weeks of age, respectively. Ipek and Scozco (2015) observed an increase in the weight of hatchlings of eggs of 45week-old mothers of $3.97 \mathrm{~g}$ compared to eggs of 30 -week-old mothers. The studies of Iqbal et al. (2016) indicated that there is a positive correlation between the age of the mothers (53 and 58 weeks) with the weight of the hatched chicks $(r=0.62)$, but when taking the equal weight of eggs from mothers aged 28 and 58 weeks, the weight of the hatched chicks to the weight of the egg was decreasing with increasing age (74.52\% and 72$) .54 \%$, respectively). The absence of differences in the weight 
of the hatched chicks without yolk does not mean that there are no differences between them. It was observed that the chicks produced from eggs of old mothers (53 weeks old) contain more protein and fat $(0.152$ and 0.046 , respectively) than the chicks produced from 29 -week-old mother's eggs ( 0.146 and 0.033 , respectively). This means that the eggs of older mothers contain high energy, especially in the large yolk.

\section{b. Fetal Metabolism}

Nutrients necessary for the development of the fetus are stored in albumin, yolk and eggshell during embryonic development, and the yolk sac is the main source of energy as a result of the oxidation of fatty acids (Speake et al., 1998). Development is prepared by the oxidation of fatty acids. The process of nutrient absorption and utilization by the fetus is affected by maternal age (Yadgary et al. 2010). In another study, the yolk sac absorption rate was $84.4 \%$ for hatched chicks from 53-week-old mothers, while this percentage was $78.8 \%$ for chicks hatched from eggs of 36-week-old mothers (Nangsuay, et al. 2011). Şahan et al. (2014) explained that the yolk sac absorption rate is high by hatched chicks from Eggs of 52-week-old mothers, as the remaining yolk sac weight was $15.1 \mathrm{~g}$, compared to hatched chicks from eggs of 36-week-old mothers, where the remaining yolk sac weight was $17.8 \mathrm{~g}$, where the percentage of yolk sac absorption for each was $81 \%$ and $78.1 \%$, respectively hatching traits

\section{- $\quad$ Egg Weight Loss}

The loss of egg weight, especially the loss of water from the egg, is an important indicator in the process of incubation of eggs (Romao et al., 2008), and it refers to the amount of biological gas exchange between the components of the egg and its external environment. The highest hatching rate (Tona et al., 2001). When the percentage of moisture lost from the egg is less than $6 \%$, it leads to a decrease in the rate of hatching and no negative effect is observed on the growth of chicks or their water content, but when the loss of water from the egg is more than $20 \%$, this leads to the depletion of the allantoic fluid. Dryness of the amniotic fluid that surrounds the fetus and dryness of the skin of the fetus (Davis et al., 1988). The factors that affect the amount of water lost from the egg are the age of the mothers (Walsh et al., 1995), the percentage of egg weight loss and the quality of its outer shell (Mróz et al., 2007).

\section{- Hatching and Genetic Mortality Rates}

The hatchability and fertility are highly dependent on the age of the mothers (Koppenol et al., 2015), where the fertility and hatchability of total eggs and fertilized eggs decrease with the age of mothers (Elibol et al., 2002, Yilmaz-Dikmen and Sahan, 2009) due to late fetal deaths and this may be due to the fact that the embryos produced from eggs Old mothers will produce relatively more heat since the 16th day of the egg incubation period due to the large size of the yolk from which higher heat is produced compared to those produced from eggs of young mothers (Nangsuay et al., 2016) and thus these embryos are at risk of late mortality (Elibol and Braka, 2008), Therefore, it can be said that the high rate of late fetal deaths with the age of the mothers is partly due to the conditions of the incubator such as heat and ventilation, which may not be suitable for the physiological characteristics of these fetuses, and this is all due to the effect of the age of the mothers. The combined effects of low ventilation and high temperature emitted from large eggs at the end of incubation may result in a rise in the temperature of the embryos and the incubator in general, causing a rise in the percentage of embryonic deaths (Tona et al., 2001). As for the early embryonic death rate, Fairchild noted and others (2002) that it increased in eggs of young mothers of age (35-32 weeks) compared to eggs of mothers of old age (50-44 weeks), as it was $7.3 \%$ and $84 \%$, respectively.

- Storage Period

a. Embryonic Development

The blastomere requires a minimum number of germ cells to begin the normal embryonic development process, as the germ disk of healthy mothers contains an average of 60,000 fetal cells at ovulation (Petitte et al., 1990).

The study of Reijrink et al. (2010) revealed that $92 \%$ of the embryos at ovulation are at an embryonic stage ranging between EG-10 and EG-12 when the maternal age is between 50-24 weeks, but this study did not explain in detail the fetal morphological changes during the long-term storage stage.

Pokhrel et al. (2018) conducted a more accurate study, where a high-resolution microscopic imaging system was used to determine the embryonic stage of the development of the germinal disc during the storage period. It was noted that the stage of embryonic development after 28 days of storage reached the 13-EG stage, which indicates the end stage of blastoderm formation. The mitotic indicator is one of the tools used to measure the length of the cell cycle and the rate of cell proliferation (Alison, 1995). The percentage of cell division and the length of its cycle increases with the increase in temperature during egg storage, as it was found that the percentage of division was equal to $8.5 \%, 4.75 \%$ and $3.4 \%$ during 
The storage period of 4 weeks of eggs at temperatures of 24,15 and $5{ }^{\circ} \mathrm{C}$, respectively (Konishi and Kosin, 1974). In a study by Pokhre et al. (2018) it was found that the rate of division of the germ disk cells of fresh eggs at ovulation is $2.3 \%$ and this rate increases to three or four times after 21 and 28 days from Storage at $18^{\circ} \mathrm{C}$. These researchers suggested that a lower storage temperature would lead to stopping the mitotic division of embryonic cells due to the low metabolic rate of these cells. These cells remain almost in a state of dormancy and have the ability to protect themselves from death better when the temperature recurs during the incubation of eggs and their chances of recovery increase compared to the rest of the cells, thus supporting the growth and survival of the embryo.

Perhaps the long dormancy state increases the aging of cells rapidly in relation to the length of storage period, and the process of natural cell death increases by the programmed death process (Konish and Riosin (1974, 1974). The incidence of programmed cell death after ovulation is approximately $3.1 \%$ and this percentage increases to $13.9 \%$ After 14 days of storing eggs at a temperature of $12^{\circ} \mathrm{C}$, which results in a decrease in the number of viable embryonic cells (Bloom and Muscarella, 1998).

Hamidu et al. (2011) showed that the percentage of live embryonic cells for eggs that were stored for 4 days was $81.17 \%$ compared to $68.18 \%$ for eggs that were stored for 14 days, where the percentage of early programmed death after long-term storage was $17.88 \%$ while it was $4.32 \%$ after 4 days of storage.

The study of Pokhrel et al. (2018) reported that the criteria of the characteristics of final broiler chicks were not different between the hatched chicks for eggs stored for a short or long period of up to 21 days of storage, but the eggs stored for a period of 28 days resulted in a slight decrease in the weight of the chicks without the yolk sac, as well as the length of the chicks at hatching, as well as the productive performance subsequent to these chicks.

\section{b. Fetal Metabolism}

The difference in the $\mathrm{pH}$ value between the white (approximately 9) and the yolk (approximately 6.5) is necessary for the transport functions through the yolk membrane (Benton and Brake, 1996). The $\mathrm{pH}$ level must be maintained during the first days of incubation between 7.9 and 8.4 for optimal embryonic development (Gillespie and McCanwell, 1987), and it must be checked whether this is possible or not. At this stage of embryonic development, the gas exchange between the embryo and its environment is low. One of the reasons for the difference between the $\mathrm{PH}$ of the albumin near the fetus and the rest of the albumin can be attributed to the close attachment to the outer shell of the egg.

The decrease in the number of germ disc cells resulting from apoptosis and necrosis during the long period of storage of the eggs may reduce the amount of $\mathrm{O} 2$ of the fetus that it consumes for the purpose of metabolic activity during the incubation period. Effective for the oxidation of carbohydrates, fats or proteins to produce the energy needed for the growth of organs (Christensen et al., 2001) and this may lead to a decrease in the weight of the fetus and hatched chicks after storing the eggs for a long time.

- Characteristics of Hatching

a. Weight of Lost Eggs

During the storage period of the eggs, the percentage of egg weight loss increases in conjunction with the length of the storage period (Goliomytis et al. 2015), but during the incubation period, the length of the egg storage period has no effect on that (Reijrink et al., 2008). The main reason for the lack of an increase in egg weight loss during the egg storage period Incubation Due to the weight of eggs lost during storage for a long time, these eggs lose most of the moisture from their internal components.

\section{b. Hatching}

The process of storing eggs before incubation can have a beneficial or harmful effect on the rate of hatching. Vick et al. (1993) noted that the hatching rate begins to decline after 7 days of storing eggs. While Schmidt et al. (2009) reported that the hatching rate for eggs of 39-week-old mothers started to decline after 4 days of egg storage, as the rate of decrease was $1.38 \%$ for each day up to 8 days of storage. Early embryonic, late fetal demise and non-hatched capsular eggs were more likely for eggs stored for 12 days (7.88\% and 3.12\%, respectively), while these percentages were for eggs stored for 2 days $(6.26 \%$ and $2.14 \%$, respectively). As for the beneficial effect of egg storage, other studies reported that eggs stored for several days had a higher hatchability rate than fresh eggs that were introduced to the incubator. Onbasilar et al., 2007). Also, the eggs produced from 32-week-old broiler mothers, which were stored for 7 days at 12 and $18{ }^{\circ} \mathrm{C}$, had a higher hatching rate of 12 and $9 \%$, respectively, than fresh eggs that were entered into the incubator immediately after the ovulation process (Pokhrel et al., 2018). This phenomenon can be explained by the occurrence of some changes that occurred during the process of storing eggs and affecting the formation of albumin (Benton and Brake, 1996). The bacterial disk is adjacent to the albumin and leads to changes in viscosity and $\mathrm{pH}$ during storage this plays a key role in determining the ability of the fetus to grow in the early stages of development. 
- The Interaction Between Maternal Age and Length of Storage

a. Embryo Quality

The survival of the fetus with its ability to grow is related to the stage of embryonic development at the time of ovulation, which in turn is affected by the position of the egg in the egg-laying chain and the rate of its passage in the oviduct during its formation, and these two factors are affected by the age of the mothers (Reijrink et al., 2008). Fasenko et al. (2001) concluded that there is an ideal stage during embryo formation that is characterized by its high ability to withstand the length of the egg storage period, and it is for the eggs of young mothers at the age of 32 weeks at the stage of EG-10.9, while the embryos of eggs of large mothers are at the age of 63 weeks at the stage of EG-12.1. This stage will increase after 28 days of storing eggs at a temperature of $18{ }^{\circ} \mathrm{C}$ to $12.9 \mathrm{EG}$ - and EG-13, respectively, meaning that the increase is more pronounced in the eggs of young mothers (Pokhrel, et al., 2018).

\section{b. Fetal metabolism}

When the embryo is in the stage of morphogenesis EG-10, the flow of oxygen gas increases to the posterior region of the germinal disc. This increase in oxygen is associated with the emergence and expansion of the plastidium (the middle region between the endodermo-ectoderm of the germinal disc). With increased cell growth in this region, cell density increases and metabolic activity increases (Radatz et al. , 1987).

With the increase in oxygen consumption by the embryonic cells, their production of $\mathrm{CO} 2$ gas will increase at the same time during early storage and incubation. on producing sufficient amount of $\mathrm{CO} 2$ compared to less developed fetuses (Reijrink et al., 2008).

The production of $\mathrm{CO} 2$ gas in a high amount by the fetus will reduce the $\mathrm{pH}$ level in the small environment of the fetus and therefore the yolk index, the strength of the yolk membranes and the high albumin in fetuses from old mothers are more affected than fetuses from young mothers (Fasenko et al., 1992).

\section{- Specifications for Hatching}

a. Weight of Lost Eggs

The amount of water lost by evaporation from the hatching eggs is affected by the length of the egg storage period and the season of egg laying (Stępińska, et al., 2017). The harmful effect of prolonged storage time is more pronounced in eggs of old mothers (Meijerhof, 1994), which may be due to a decrease in albumin specifications at the time of ovulation and a continuing decrease during the egg storage process (Lapaõ et al., 1999). The increase in the $\mathrm{pH}$ of albumin is associated with an increase in the length of the storage period of eggs and the age of the mothers, as well as a decrease in the height of the albumin and its viscosity and an increase in its fluidity (Brake et al., 1997). The increase in water evaporation from the egg contents may be related to the egg shell, which is lighter as the age of mothers increases (1976, Roland). Regarding the weight loss of eggs during the incubation period, Reis et al. (1997) reported that the progression of embryonic development up to 18 days of incubation leads to an increase in heat production from the fetus due to an increase in metabolic processes, which increases the temperature of the fetus and increases the pressure of water vapor inside the egg, which leads to the eggs of older mothers It will contain embryos with high embryonic development, so the contents of the egg will lose more water during the incubation period compared to the eggs of young mothers.

\section{b. Hatchability}

The observations of Pokhrel et al. (2018) reinforced that the hatchability rate for fertilized eggs from young mothers at 30 weeks of age was $89.7 \%$ when the eggs were stored for 7 days and higher than the eggs that were stored for 3 days, as the percentage was $87.5 \%$ and the hatching rate for eggs that were stored for the same The duration of the 53-week-old mothers was $92.2 \%$ and $90.1 \%$, respectively, while storing eggs for 14 days led to a decrease in the hatching rate of all age groups. From storage at 18 and $12{ }^{\circ} \mathrm{C}$ at $12 \%$ and $9 \%$, respectively. While storing eggs for 14 days led to a decrease in the hatching rate of all age groups, the percentage of the decrease was higher in the eggs of old mothers. It was also noted that the hatching rate began to decrease for young mothers ( 32 weeks old) after 7 days of storage at a temperature of 18 and $12{ }^{\circ} \mathrm{C}$ by $12 \%$ and $9 \%$ in a row. The decrease in hatching rate was high in the eggs of young and old mothers, so the hatching rate started to decrease by $1 \%$ and $8 \%$ per day/storage for the eggs of young mothers after storing them at a temperature of $12^{\circ} \mathrm{C}$ for 21 and 28 days, respectively. As for the eggs of old mothers, the rate of hatching began to decrease after 14 days of storing eggs by $9 \%, 27 \%$ and $28 \%$ after 14, 21 and 28 days of storage, respectively. Elibol et al. (2002) observed a decrease in hatching rate for eggs of young mothers ( 31 weeks) and eggs of old mothers (50 weeks) after increasing the period of egg storage from 3 to 7 days to $1.7 \%$ and $3.7 \%$, respectively. Lapaõ et al. (1999) advised that it is preferable to store eggs of young mothers rather than eggs of old mothers. This result was based on an experimental design that included four mothers' ages ranging from 3259 weeks and four storage periods ( $8-5$ days).

\section{CONCLUSIONS}

This study concludes that the effect of storage on egg characteristics and embryo survival depends on the length of storage and the age of the mothers. Increasing the length of egg storage for more than 7 days has a negative effect on egg specifications, as it leads to a decrease in hatchability. The lower hatching rate is higher when the mothers are 50 weeks of 
age and more compared to the young mothers. Storing the eggs of young mothers (less than 35 weeks) for a short period of less than 7 days will increase the hatching rate. The duration of egg storage and storage conditions must be determined based on the age of the mothers herd to keep the embryos alive as much as possible during the incubation period. Its development is stabilizing naturally.

\section{REFERENCES}

[1] Alison, M. 1995. Review: Assessing cellular proliferation: What's worth measuring? Human and Experimental Toxicological. 14: 935-944. https ://doi.org/ 10.1177/ 096032719501401201

[2] Benton, C. E., \& Brake, J. 1996. The effect of broiler breeder flock age and length of egg storage on egg albumen during early incubation. Poultry Science. 75: 1069-1075. https ://doi.org/10.3382/ps.0751069

[3] Bloom, S. E., \&Muscarella, D. E. 1998. Stress responses in the avian early embryo: Regulation by pro- and anti-apoptotic cell death genes. Poultry Avian Biology. 9(2): 43-55.

[4] Brake, J., Walsh, T. J., Benton, C. E., Petitte, J. N., Meijerhof, R., \&Pealva G. 1997. Egg handling and storage. Poultry Science. 76: 144-151.https ://doi.org/ 10.1093/ps/ 76.1.144.

[5] Burley, R. W., \& Vadehra, D. V. 1989. The albumen: chemistry. In: R. W Burley, \& D. V. Vadehra (Eds.), The avian egg $(65-128)$. New York, NY: Wiley

[6] Christensen, V. L., Wineland, M. J., Fasenko, G. M., \& Donaldson, W. E. 2001. Egg storage effects on plasma glucose and supply and demand tissue glycogen concentrations of broiler embryos. Poultry Science. 80: 1729-1735. https ://doi.org/10.1093/ps/80.12.1729.

[7] Christensen, V. L., Wineland, M. J., Fasenko, G. M., \& Donaldson, W. E. 2002. Egg storage alters weight of supply and demand organs of broiler chicken embryos. Poultry Science.81: 1738-1743. https ://doi. org/10.1093/ps/81.11.1738.

[8] Damaziak, K., Marzec, A., Riedel, J., Szeliga, J., Koczywąs, E., Cisneros,F., Lenart, A. 2018. Effect of dietary canthaxanthin and iodine on the production performance and egg quality of laying hens. Poultry Science. 97(11): 4008-4019. https ://doi.org/10.3382/ps/pey264

[9] Davis, T. A., Shen, S. S., \& Ackerman, R. A. 1988. Embryonic osmoregulation:Consequences of high and low water loss during incubation of the chicken egg. Journal of Experimental Zoology. 245(2): 144-156. https ://doi.org/10.1002/jez.14024 50205

[10] Elibol, O., \& Brake, J. 2008. Effect of egg weight and position relative to incubator fan on broiler hatchability and chick quality. Poultry Science. 87: 1913-1918. https ://doi.org/10.3382/ps.2008-00014

[11] Elibol, O., Peak, S. D., \& Brake, J. 2002. Effect of flock age, length of egg storage, and frequency of turning during storage on hatchability of broiler hatching eggs. Poultry Science. 81: 945-950. https ://doi.org/10.1093/ps/81.7.945.

[12] Fairchild, B. D., Christensen, V. L., Grimes, J. L., Wineland, M. J., \&Bagley,L. G. 2002. Hen age relationship with embryonic mortality and fertility in commercial turkeys. The Journal of Applied Poultry Research.11: 260-265. https ://doi.org/ 10.1093/japr/11.3.260.

[13] Fasenko, G. M., Robinson, F. E., Hardin, R. T., \& Wilson, J. L. 1992. Variability in preincubation embryonic development in domestic fowl. 2. Effects of duration of egg storage period. Poultry Science. 71,2129-2132. https ://doi.org/10.3382/ ps.0712129

[14] Fasenko, G. M., Robinson, F. E., Whelan, A. I., Kremeniuk, K. M., \&Walker, J. A. 2001. Prestorage incubation of long-term stored broiler breeder eggs: 1. Effects on hatchability. Poultry Science. 80:1406-1411. https ://doi.org/ 10.1093/ps/80.2.132

[15] Fasenko,G.M.2007. Egg Storage and the Embryo. PoultrySci.J. 86:1020-1024.

[16] Freeman, B. M., \& Vince, M. A. 1974. Development of the avian embryo:Abehavioural and physiological study. London, UK: Chapman and Hall.

[17] Gillespie, J. I., \&Mchanwell, S. 1987. Measurement of intraembryonic pH during the early stages of development in the chick embryo. Cell Tissue Research. 247:445-451. https ://doi.org/10.1007/BF00218326

[18] Goliomytis, M., Tsipouzian, T., \& Hager-Theodorides, A. L. 2015. Effects of egg storage on hatchability, chick quality, performance and immune competence parameters of broiler chickens. Poultry Science. 94:2257-2265.https ://doi.org/ 10. $3382 /$ ps/pev200.

[19] Hamidu, J. A., Uddin, Z., Li, M., Fasenko, G. M., Guan, L. L., \&Barreda, D. R. 2011. Broiler egg storage induces cell death and influences embryo quality. Developmental Biology. 90: 1749-1757. https ://doi.org/10.3382/ps.2011-01361.

[20] Heath, J. L. 1975. Investigation of changes in yolk moisture. Poultry Science. 54: 2007-2014. https ://doi.org/10.3382/ps.0542007.

[21] Ipek, A., \&Sozcu, A. 2015. The effects of broiler breeder age on intestinal development during hatch window, chick quality and first week broiler performance. Journal of Applied Animal Research. 43:402-408. https ://doi.org/10.1080/09712 119.2014.978783

[22] Iqbal, J., Khan, S. H., Mukhtar, N., Ahmed, T., \& Pasha, R. A. 2016. Effects of egg size (weight) and age on hatching performance and chick quality of broiler breeder. Journal of Applied Animal Research.44: 54-64. https ://doi.org/10.1080/09712 119.2014.987294.

[23] Kato, A., Nakamura, R., \& Sato, Y. 1970. Studies on changes in stored shell eggs. Part V. The difference in the chemical and physicochemical properties of ovomucin (B) between the thick and thin white. Agricultural and Biological Chemistry. 34 : 854-859. https ://doi.org/10.1271/bbb19 61.34.854

[24] Kato, S., Okamura, M., Shimamoto, N., \&Utiyama, H. 1981. Spectral evidence for a rapidly formed structural intermediate in the refolding kinetics of hen egg-white lysozyme. Biochemistry.20: 51080-51085.https ://doi.org/10.1021/bi005 08a006

[25] Konishi, T., \&Kosin, I. L. 1974. Morbidity of aging non-incubated chicken blastoderms: Further cytological evidence and interpretation. Journal of Embryology and Experimental Morphology. 32: 557-571

[26] Koppenol, A., Delezie, E., Wang, Y., Franssens, L., Willems, E., Ampe,B., ... Everaert, N. 2015. Effects of maternal dietary 
EPA and DHA supplementation and breeder age on embryonic and post-hatch performance of broiler offspring: Age and n-3 PUF Aaffect embryonic and post-hatch performance. Journal Animal Physiology and Anima 1Nutrition. 99: 36-47. https ://doi.org/10.1111/jpn.12308

[27] Lapaõ, C., Gama, L. T., \& Soares, M. C. 1999. Effects of broiler breeder age and length of egg storage on albumen characteristics and hatchability. Poultry Science.78: 640-645. https ://doi.org/10.1093/ps/78.5.640.

[28] Li-Chan, E. C. Y., Powrie, W. D., \&Nakai, S. 1995. The chemistry of eggs and egg products. In W. J. Stadelman, \& O. J. Cotterill (Eds.).Egg science and technology. 4: 109-160. New York, NY: Food Products Press.

[29] Meijerhof, R. 1994. The storage of hatching egg. In Proceedings of the First International Incubation Conference:2-5. Utrecht, the Netherlands: Positive Action Publications Ltd. ISBN 90-74489-13-3

[30] Mróz, E., Katarzyna Michalak, K., \&AnetaOrłowska, A. 2007. Embryo mortality and poult quality depend on the shell structure of turkey hatching eggs. Animal Science Papers and Reports. 25: 161-172. https://doi.org/10.1093/ps/82.3.357

[31] Mueller, W. 1959. Factors affecting the quality loss in egg albumen during storage. Poultry Science.38:843-845. https ://doi.org/10.3382/ps.0380843.

[32] Nangsuay, A., Meijerhof, R., Van den Anker, I., Heetkamp, M. J. W., De Souza Morita, V., Kemp, B., \& Van den Brand, H. 2016. Effects of breeder age, broiler strain, and eggshell temperature on development and physiological status of embryos and hatchlings. Poultry Science. 95: 1666-1679. https ://doi.org/10.3382/ ps/pew080

[33] Nangsuay, A., Ruangpanit, Y., Meijerhof, R., \&Attamangkune, S. 2011. Yolk absorption and embryo development of small and large eggs originating from young and old breeder hens. Poultry Science. 90:2648-2655. https ://doi.org/ 10.3382/ps.2011-01415.

[34] Noble, R. C., \& Cocchi, M. 1990. Lipid metabolism and the neonatal chicken. Progress in Lipid Research. 29: 107-140. https ://doi.org/10.1016/0163-7827(90) 90014-C

[35] Nowaczewski, S., Kontecka, H., Rosinski, A., Koberling, S., \&Koronowski, P. 2010. Egg quality of Japanese quail depends on layer age and storage time. Folia Biologica. 58: 201-207. https ://doi.org/10.3409/fb58_3-4.201-207.

[36] Okur, N., Eleroğlu, H., \&Türkoğlu, M. 2018. Impacts of breeder age,

[37] storage time and setter ventilation program on incubation and posthatch performance of broilers. Brazilian Journal of Poultry Science. 20: 27-36.

[38] Onbasilar, E. E., Poyraz, Ö., \&Erdem, E. .2007. Effects of egg storage period on hatching egg quality, hatchability, chick quality and relative growth in Pekin ducks. ArchivfürGeflügelkunde. 71: 187-191.https://doi.org/10.1590/1806-9061-20170550

[39] Petitte, J., Clark, M. E., Liu, G., VerrinderGibbins, A. M., \& Etches, R. J. 1990. Production of somatic and germline chimeras in the chicken by transfer of early blastodermal cells. Development. 108: 185-189.

[40] Pokhrel, N., Ben-Tal Cohen, E., Genin, O., Ruzal, M., Sela-Donenfeld, D.,\& Cinnamon, Y. 2018. Effects of storage conditions on hatchability,embryonic survival and cytoarchitectural properties in broiler from young and old flocks. Poultry Science. 97:1429-1440. https ://doi.org/10.3382/ps/pex393.

[41] Radatz, E., Eyal-Giladi, H., \& Kucera, P. 1987. Patterns of oxygen consumption during establishment of chephalocaudal polarity in the early chick embryo. Journal of Experimental Zoology Supplement. 1:213-218.

[42] Reijrink, I. A. M., Berghmans, D., Meijerhof, R., Kemp, B., \& van den Brand, H. 2010. Influence of egg storage time and preincubation warming profile on embryonic development, hatchability, and chick quality. Poultry Science. 89: 1225-1238. https ://doi.org/10.3382/ps.2009-00182

[43] Reijrink, I. A. M., Meijerhof, R., Kemp, B., \& Van den Brand, H. 2008. The chicken embryo and its microenvironment during egg storage and early incubation. World's Poultry Science Journal. 64: 581-598. https ://doi.org/10.1017/S0043 93390 8000214

[44] Reis, L. H., Gama, L. T., \&ChaveiroSoares, M. 1997. Effects of short storage conditions and broiler breeder age on hatchability, hatching time, and chick weights. Poultry Science. 76: 1459-1466. https ://doi.org/10.1093/ps/76.11.1459

[45] Roland, D. A. 1976. Recent developments in egg shell quality. Feedstuffs. 48(29): 31-32.

[46] Romao, J. M., Moraes, T. G. V., Teixeira, R. S. C., Cardoso, W. M., \&Buxade, C. C. 2008. Effect of egg storage length on hatchability and weight loss in incubation of egg and meat type Japanese quails. Brazilian Journal of Poultry Science. 10:143147. https ://doi.org/10.1590/S1516-635X2 008000300001

[47] Şahan, U., Ipek, A., \&Sozcu, A. 2014. Yolk sac fatty acid composition, yolk absorption, embryo development, and chick quality during incubation in eggs from young and old broiler breeders. Poultry Science.93: 2069-2077. https ://doi.org/ 10. 3382/ps.2013-03850

[48] Schaal, T. and G. Cherian .2007. A survey of the hatchability of broiler and turkey egg in the United States from 1985 through 2005. Poultry Sci.J. 86:598-600.

[49] Schmidt, G. S., Figueiredo, E. A. P., Saatkamp, M. G., \&Bomm, E. R. 2009. Effect of storage period and egg weight on embryo development and incubation results. Brazilian Journal of Poultry Science. 11: 1-5. https://doi.org/10.1590/S1516635X200900010000110.3382/ps.0720251

[50] Scott, T. A., \& Silversides, F. G. 2000. The effect of storage and strain of hen on egg quality. Poultry Science.79:1725-1729. https ://doi.org/ 10. 1093 /ps/ 79.12 .1725

[51] Sell, J. L., Angel, C. R., \&Escribano, F. 1987. Influence of supplemental fat on weights of eggs and yolks during early egg production. Poultry Science. 66: 1807-1812. https ://doi.org/10.3382/ps.0661807

[52] Speake, B. K., Noble, R. C., \& Murray, A. M. B. 1998. The utilization of yolk lipids by the chicks embryo. World's Poultry Science Journal. 54:319-331. https ://doi.org/10.1079/WPS19 980022

[53] Stępińska, M., Mróz, E., Krawczyk, M., Otowski, K., \&Górska, A. 2017.Effect of hen age and storage time on egg weight loss and hatchability results in turkeys. Annal Animal Science. 17: 447-462. https ://doi.org/10.1515/aoas-2016-0057

[54] Tona, K., Bamelis, F., Coucke, W., Bruggeman, V., \&Decuypere, E. 2001. Relationship between broiler breeder's age and egg weight loss and embryonic mortality during incubation in largescale conditions. The Journal of Applied Poultry Research. 
[55] Tona, K., Onagbesan, O., De Ketelaere, B., Decuypere, E., \& Bruggeman,V. 2004. Effects of age of broiler breeders and egg storage on egg quality, hatchability, chick quality, chick weight, and chick posthatch growth to forty-two days. The Journal of Applied Poultry Research.13(1):10-18. https ://doi.org/10.1093/japr/13.1.10

[56] Uddin, Z., \&Hamidu, J. A. 2014. Prolong egg storage affects broiler breeder embryonic metabolism and chick quality. Journal of Animal Science Advances. 4(7): 973-977. https ://doi.org/10.5455/jasa.20140 713053547

[57] Ulmer-Franco, A. M., Fasenko, G. M., \& O’Dea Christopher, E. E. 2010. Hatching egg characteristics, chick quality, and broiler performance at 2 breeder flock ages and from 3 egg weights. Poultry Science. 89:2735-2742. https ://doi.org/ 10. 3382/ps.2009-00403

[58] Vick, S. V., Brake, J., \& Walsh, T. J. 1993. Relationship of egg storage time, storage conditions, flock age, eggshell and albumen characteristics, incubation conditions and machine capacity to broiler hatchability. Zootechnology International. 16: $30-41$.

[59] Walsh, T. J., Rizk, R. E., \& Brake, J. 1995. Effects of storage for 7 or 14 days at two temperatures and the presence or absence of carbon dioxide on albumen characteristics, weight loss and early embryonic mortality of broiler hatching eggs. Poultry Science.74: 1403-1410.https ://doi.org/10.3382/ps.0741403

[60] Yadgary, L., Cahaner, A., Kedar, O., \& Uni, Z. 2010. Yolk sac nutrient composition and fat uptake in late-term embryos in eggs from young and old broiler breeder hens. Poultry Science. 89: 2441-2452. https ://doi.org/10.3382/ps.2010-00681

[61] Yilmaz-Dikmen, B., \&Sahan, U. 2009. The relationship among age, yolk fatty acids content, and incubation results of broiler breeders. Poultry Science. 88: 185-190. https ://doi.org/10.3382/ps.2008-00068 